\title{
Mini-Review \\ The importance of animal studies in Exercise Science
}

\author{
Kátia De Angelis \\ Universidade Nove de Julho, São Paulo, SP, Brasil \\ Bruno Rodrigues \\ Universidade Estadual de Campinas, Campinas, SP, Brasil \\ Angelina Zanesco \\ Universidade Estadual Paulista "Júlio de Mesquita Filho", Rio Claro, SP, Brasil \\ Universidade "Camilo Castelo Branco", Fernandópolis, SP, Brasil \\ Edilamar Menezes de Oliveira \\ Fabiana de Santa Anna Evangelista \\ Universidade de São Paulo, São Paulo, SP, Brasil \\ Helio Jose Coelho Junior \\ Maria Andreia Delbin \\ Universidade Estadual de Campinas, Campinas, SP, Brasil \\ Patricia Chakur Brum \\ Paulo Rizzo Ramires \\ Universidade de São Paulo, São Paulo, SP, Brasil \\ Pedro Paulo Soares \\ Universidade Federal Fluminense, Niterói, RJ, Brasil \\ Rogério Brandão Wichi \\ Universidade Federal de Sergipe, São Cristóvão, SE, Brasil \\ Sandra Lia do Amaral \\ Universidade Estadual Paulista “Júlio de Mesquita Filho”, Bauru, SP, Brasil \\ Iris Callado Sanches \\ Universidade São Judas Tadeu, São Paulo, SP, Brasil
}

\begin{abstract}
The validity and relevance of research with animals for the development of knowledge in Exercise Science have for long been discussed. Given the complexity of the biological systems, the use of animal models offers a significant contribution to uncover new findings about acute and chronic effects of exercise, particularly when these studies in humans have limitations and ethical implications. There have been notable findings using experimental animals either in basic sciences or in clinical studies involving physiology, pharmacology, genetic, biochemistry, urology, endocrinology and cancer. This article presents a brief review of scientific research using animal models with a focus on exercise training as an effective tool for the prophylaxis and treatment of different pathological processes, which are the basis of many concepts taught and used in undergraduate courses and graduate programs, as well as in new researches showed in scientific conference meetings in numerous areas of science.
\end{abstract}

Keywords: animal studies, exercise science, physical education, sport, knowledge evolution.

\section{Introduction}

For some time now in Brazil, researchers have been discussing the validity and relevance of using animal models in studies focusing on Exercise Science. It should be noted that most of the experimental trials undertaken to assess the effects of exercise have so far aimed at evaluating their impact on intact organisms, and the few trials using human models have been generally said to be more reliable. However, the more frequent use of humans in these studies would not be either possible 
or desirable in most cases, since they would require a much extended life-long follow-up of humans, which would not be feasible (mainly because of the high percentage of participants expected to drop out), or the use of invasive procedures, which would raise ethical questions. Studies examining the impact of exercise training on function of different cells or tissues are therefore carried out in animals whenever questions about the feasibility of using humans are raised. Besides, researches using animal models are also conducted for further understanding of the biology of the animals themselves, as well as improving their health.

Studies using animal models in which one can control environmental, psychological and emotional factors have contributed to scientific fields, such as medicine, pharmacy, nutrition and psychology. These results have been fundamental in developing scientific knowledge and improving the quality of life of people. Given the complexity of biological systems, the use of animal models has provided a significant understanding of the various adaptive mechanisms undergoing acute and chronic physical exercise, particularly when ethical considerations make the use human models unfeasible.

Thus, this review paper aimed to survey a corpus of studies using animal models, which have grounded many of the concepts taught at Physical Education and Sports undergraduate courses, and have contributed to a range of research studies in this area. The review also aimed to raise awareness among scholars and professionals about the importance of this largely consolidated approach and emphasize fundamental ethical principles concerning the use of animals in building a solid knowledge base on Exercise Science.

\section{Research using animal models in Exercise Sciences: a brief overview}

Long time ago studies have been conducted using animals to a better understanding of the structure and functioning of the body. One of the first formal studies using animal models found in the literature was conducted by Harvey (1628), who described that the heart pumped the blood in a circular, unidirectional way, from the arteries to the veins and back to the heart 1 . In 1849, Regnault and Reiset estimated the respiratory quotient (RQ) of animals using a closed-circuit spirometry 2. Based on findings obtained from the study, a relationship between body weight and metabolic rate was established, which gave birth to the Surface Area Law and allometric scaling, still currently used.

A hallmark in Exercise Physiology was the first volume of the American Journal of Physiology, published in 1898, and edited by Porter, a cardiovascular physiology specialist. Three papers on Exercise Physiology using animal models were featured in this first issue: "Spontaneous physical activity in rodents and the influence of diet", "Neural control of muscular movement in dogs" and "Perception of muscular fatigue and physical activity" ". In the following four issues of the Journal (1898-1901), six papers covered topics related to Exercise Physiology from labs using animal models ${ }^{3}$. Some years later, other important
Journals emerged: the Physiological Review, in 1921; the Journal of Applied Physiology in 1948; and later, the renowned Medicine and Science in Sports, whose name was changed to Medicine and Science in Sports and Exercise in 1980.

Almost a century later in Brazil, the Revista Paulista de Educação Física (later called Revista Brasileira de Educação Física) was first published in January, 1988. In 1995, the Journal published the first study using animal models: "Dosagem histaminica muscular em ratos exercitados". The Journal of Physical Education-Motriz was first published in 1995, and a study featured in this first issue "Effects of protein-calorie malnutrition in response to acute exercise (single section) metabolic parameters" ${ }^{4}$ data from animal models.

From the 20th century onwards, the knowledge base obtained by animal studies contributed significantly to consolidate Exercise Science. Fletcher and Hopkins, in 1907, were the first to report and account for the anaerobic metabolism in vivo of a frog muscle ${ }^{5}$. Another important researcher in the advancement of Exercise Physiology was Krogh, who was awarded the Nobel Prize in 1920 for determining the blood flow in the frog skeletal muscles during contraction and at rest ${ }^{6,7}$.

Hill was awarded the Nobel Prize in 1922 for the discovery of the chemical and mechanical processes involved in muscular contraction. He also used frogs as animal models ${ }^{8}$. Benedict, who had developed, along with Harris, a formula to estimate basal energy expenditure, published in 1938 a study on the relative caloric expenditure among different species, from birds to large mammals such as the elephant ${ }^{9}$.

Current knowledge on energy metabolism is owed to Krebs, who described for the first time in 1937 the citric acid cycle (Krebs Cycle). The cycle emerged from studies carried out in the pectoral muscles of pigeons ${ }^{10}$. This discovery remains a hallmark in metabolic biochemistry, and Krebs was granted a Nobel Prize in Medicine in 1953. Later, in 1950, Lehninger and Kennedy, using isolated rat liver mitochondria, demonstrated that the reactions in the citric acid cycle take place in this organelle ${ }^{11}$.

By the same time the renowned Swedish physiologist Astränd conducted several experimental studies examining effects of exercise training on hemodynamic and autonomic nervous system in rats ${ }^{12,13}$. While Astränd and other researchers prioritized clinical studies, they also undertook many studies using animal models to understand human physiology better.

Tipton, an important researcher in Exercise Physiology, has been working for decades with both humans and animals, investigating the effects of exercise training on heart rate focus on bradycardia ${ }^{14}$. He also studied the effects of training on the blood flow of dogs, and the impact of microgravity on the physical performance of rats ${ }^{15,16}$, along with some comparative research ${ }^{17,18}$, which contributed towards a fuller understanding of the circulatory system.

Costill is another important American researcher who made use of both human and animal models. His studies shed new light on glycogen storage in skeletal muscle cells of trained rats and variations in water ${ }^{19}$, as well as glucose intake ${ }^{20}$, and changes in oxidative capacity, glycogen content and skeletal muscle tone ${ }^{21}$. The American researcher McArdle carried out 
key studies on muscle contractility and oxidative stress using both human and animal models ${ }^{22,23}$. Saltin, who has long been studying the metabolic process involved in exercise training, assessed oxygen consumption in camels at rest and during exercise ${ }^{24}$, metabolic responses to maximal exercise ${ }^{25}$. He also researched the physiological and biochemical responses of horses undergoing exercise training at varying speed and duration ${ }^{26}$.

In 1998, Kraemer studied the effects of resistance exercise on the bone tissue of rats ${ }^{27}$. Among his many studies, Faulkner also dealt with contractility and muscle regeneration in older ${ }^{28}$ and younger rats ${ }^{29}$. Holloszy, a well-known researcher in the field of skeletal muscle, has been working on animal models for years in an attempt to understand the response of skeletal muscle to exercise training in rats ${ }^{30}$. Zatsiorsky, a leading researcher in Biomechanics, analyzed the muscle demands and reactions of cats performing consecutive steps ${ }^{31}$.

Several relevant findings were obtained in studies using animal models, such as blood and cardiac disorders, hemodynamic adaptations, changes in the arterial baroreceptors, $\mathrm{O}_{2}$ consumption and heart rate of trained dogs ${ }^{32-35}$. Taking together, these studies offered a solid basis for a clearer understanding of the adaptations promoted by exercise training in humans.

Basic electric proprieties of the myocardium were first found in the ventricle of frogs ${ }^{36}$, and one of the first descriptions of the processes involved in the ATP degradation in the mitochondria was carried out in rats ${ }^{37}$. Likewise, the techniques to isolate the nuclei of muscle fibers, the key to understand adjustments promoted by exercise, were firstly tried out in the diaphragm of rats ${ }^{38}$.

Research using animal models contribute to the understanding of the metabolic mechanisms and the use of glucose during exercise ${ }^{39}$. Heat and exercise-induced changes in plasma enzymes were detected in studies using dogs. More recently, the mechanism controlling muscle development and growth via myostatin was first explained by studying lineage determination in beef cattle ${ }^{40,41}$.

The use of animal models was also useful in studying diseases affecting athletes, e.g., cardiac hypertrophy. The first studies in the area estimated the diameter of rat cardiomyocytes presenting cardiac hypertrophy ${ }^{42}$; the association between cardiomyopathy and the hypertrophy of type II fibers was first demonstrated in dogs, while cardiac hypertrophy following muscle stress was assessed in rats ${ }^{43}$. Furthermore, genetically modified animals have been used to provide a better understanding of the intracellular pathways signaling activated by physiological cardiac hypertrophy induced by exercise training ${ }^{44}$.

The usefulness of animal models has long been acknowledged in the studies undertaken in the area of Exercise Science, being regarded as a key element in promoting understanding and improving the health status of athletes and the population in general. Animal models are currently widely used and supported by research centers worldwide, including the renowned American College of Sports Medicine (ACSM), which every year awards the most relevant studies and notable researchers 45. Among the recipients of the ACSM awards, we may find Hagberg, Cooper, Laughlin, Pollock, Dempsey, Wilmore,
Saltin, Costill, Tipton, Faulkner, Holloszy, amongst other great researchers.

\section{Experimental research with animals in the field of Exercise Sciences in Brazil}

When compared to other academic areas, research in Exercise Sciences in Brazil is quite recent. The first studies were published almost forty years ago. Moreover, the first researchers of this area achieved their postgraduate degrees - Master (i.e., MSc) and Doctoral $(\mathrm{PhD})$ - in other areas, such as Pharmacy, Engineering, Psychology, and more often, Physiology and Medicine. From the 1990s onwards, research in Exercise Science started to build its own identity, with many researchers emerging from undergraduate courses in the area.

Currently, there are not many institutes for basic research on Exercise Science in Brazil, since it is a recent field of interest in research and has been little widespread. However, many researchers have collaborated for the growth of this area in Brazil, publishing papers, as well as members of the editorial board of high-impact national and international journals, and integrating the committee of scientific societies in Physical Education and related areas worldwide. Furthermore, research collaboration has been established with prestigious academicscientific laboratories from different countries in an attempt to examine deeply the molecular mechanisms by which physical exercise can exert on the cells using molecular biology tools.

Moreover, many researchers supervise graduate students and an increasing number of studies using animal models have been undertaken, reinforcing thus the key role of animal models in investigations associated with physical activity and sports in Brazil. Brazilian official funding agencies have acknowledged the importance of the studies being conducted, granting more scholarships and support to research groups working with animal models.

Figure 1A shows the global growth in the number of publications in Medline involving the crossing of the keywords "Physical activity" and "animal". Similar behavior can be observed when it was included the keyword "Brazil" to this survey (Figure 1B). In this Figure, it can be observed a sharp increment in research published from 1997 onwards in Brazil (Figure 1B), while for Exercise Science worldwide this increase may be observed from 1967 onwards (Figure 1A). These numbers clearly show how recent the area is in Brazil. This later growth may be also due to the emergence of Graduate Programs in the 90s in Brazil, which boosted research in general and the number of published articles ${ }^{46}$.

As can be seen in Table 1, the different crosses of the keywords: "physical activity", "exercise" or "sport" to "animal", "rat" or "mice" in "Brazil" resulted in a significant number of articles published in Medline. In the international ranking of scientific production in all academic areas, Brazil occupied the 13th position in 2009 (nearly $2.7 \%$ of the articles published worldwide) $)^{46}$. 
$\Delta$ Published research about "physical activity" and "animal" in the world

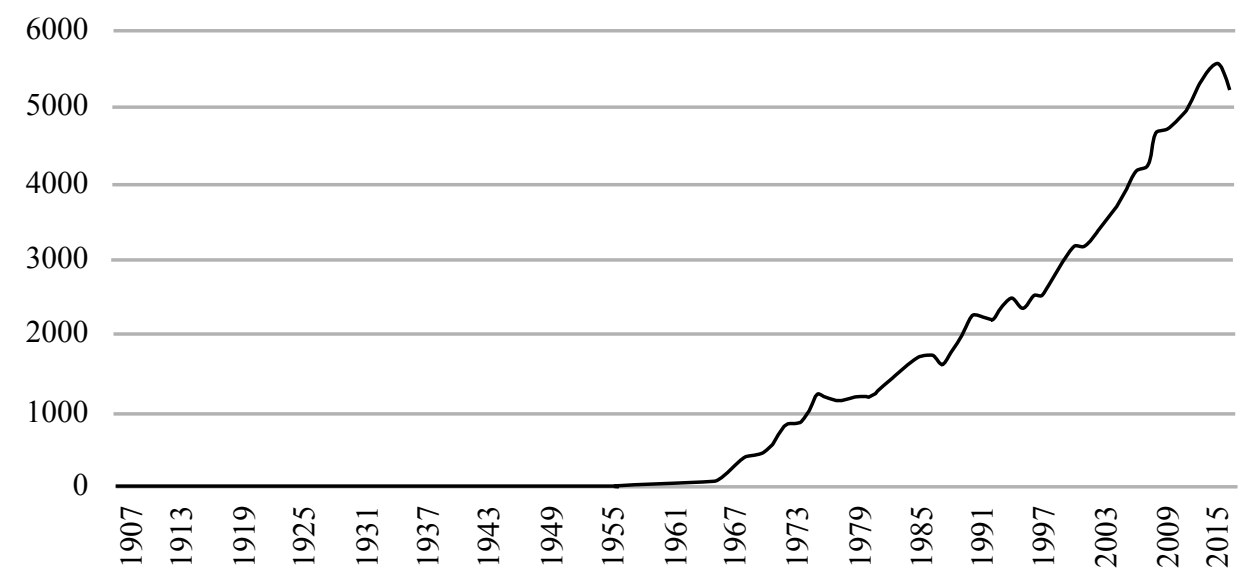

B Published research about "physical activity" and

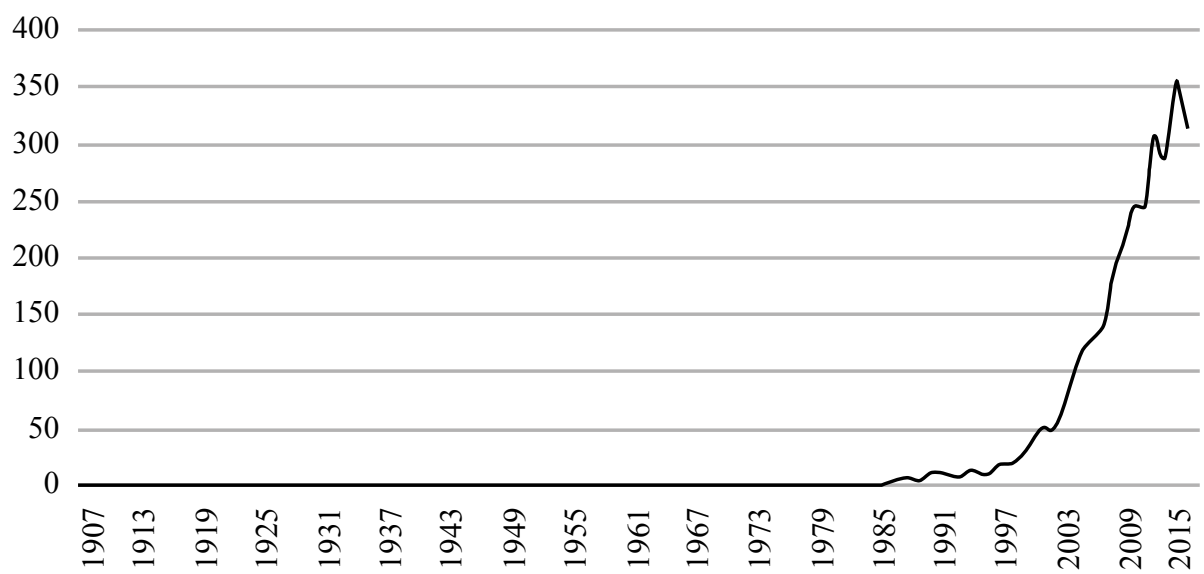

Figure 1. (A) Illustrates the increase (1907-2015) in the number of articles available at Medline using the keywords "Physical activity" and "animal", our search yielded 120,628 articles. (B) When the word "Brazil" was added in the survey, we obtained 2,993 articles in this period, i.e., nearly $2.5 \%$ of all articles found.

Table 1. Search result aggregating the key-words: "physical activity", "exercise" or "sport" with "animal", "rat" or "mice" in "Brazil".

\begin{tabular}{cccc}
\hline & Animal* & Rats & Mice \\
\hline Physical activity & 2993 & 1802 & 868 \\
Exercise & 1487 & 993 & 327 \\
Sport & 825 & 478 & 226 \\
\hline
\end{tabular}

* humans were not included

Research using animal models: ethical considerations

The use of animal models plays a key role in scientific knowledge, as it allows a better understanding of Physiology,
Biochemistry, and behavior, and enables researchers to understand the aetiopathogeny of diseases and improve methods of prevention, diagnosing and treatment (both pharmacological and non-pharmacological). A first ethical consideration should be the choice of suitable species for answering a research question. In this sense, rodents such as rats and mice are the most commonly selected for experimental research. They share some physiological features with humans and have a very short lifespan (two to three years) ${ }^{47}$. The short life of rodents makes it easier to study age-related diseases or chronic degenerative disorders. Furthermore, the small physical structure of the rodents favors their production and maintaining. 
Although small species have been largely used in research, large animals can also be useful mainly based on the high similarity with humans. Thus, horses are an excellent model for health and performance studies, whereas pigs are primary used for lipid metabolism, obesity and metabolic syndrome. Moreover, sheep are an excellent model for studying the interaction of pregnancy and exercise. In addition to these animals, dogs are also used, despite having higher heart and ventilatory capacity, higher proportion of slow-twitch fibers (i.e., type I) and lower lactate concentration than humans. Furthermore, rabbits, hamsters, cats and snakes, which generally require the utilization of reward to perform the exercise (like food), were also used in studies in Exercise Science ${ }^{48}$.

One clear advantage that deserves attention about the utilization of animal models in research is the fact that they can be maintained in extremely controlled environments, enabling thus the isolation of variables responsible for the functioning of the organic system; which is not possible in human beings. This characteristic enables the utilization of a low sample size to reach reliable results. Recently, advances in genetic engineering and biomolecular techniques have been extensively collaborating in the creation of new opportunities to study the complex phenotypes within the context of the intact animal. In fact, there is a growing interest in the study of genetically modified animals, since - with this model — it is possible to investigate candidate genes responsible for high responsivity to physical stimulus, collaborating to the understanding of the superior adaptability showed by some people, regarding physical performance and health.

However, it should be clear that the decision to use animals in research studies requires critical thinking, sound judgment, and careful analysis. In this sense, we should remember that the use of animals is a privilege granted to the research community by the society, which have expectations that such a choice will generate new knowledge and contribute to animal and human welfare ${ }^{49,50}$.

The replacement, refinement and reduction (the $3 \mathrm{Rs}$ ) strategy put forward by W.M.S. Russell e R.L. Burch in 1959 is an effective method for implementing the principles above described. Replacement refers to the possibility of substituting animal by other methods, such as in vitro studies, mathematical models, cell/tissue culture, computer simulation, among others. Refinement emphasizes the importance of developing new techniques to mitigate the pain and suffering of animals, and involves proper analgesia and asepsis in the pre-, trans - and post-operative measures. Reduction would imply fewer studies using animals, fewer animals in the studies, and improved statistical treatment ${ }^{51}$.

Currently, the 3 Rs principle is a globally accepted approach to the decision-making process of using animals in a study, in designing study groups, and in using techniques and protocols, thus complying with ethical considerations in studies involving animals.

In Brazil, the law 11,794, the decree 6,899, and other complementary normative established by the Conselho Nacional de Controle de Experimentação Animal (CONCEA-MCTIC), regulating the production, maintaining and utilization of animals of the phylum Chordata, subphylum Vertebrata, except human beings, in teaching activities and scientific research throughout the country ${ }^{52}$. One of the main regulations refers to the necessity of a previous evaluation and authorization of the Ethics Committee on Animal Use to starts researchers with animal models. In this sense, it is important to emphasize that research projects using animals will be mainly evaluated on the basis of the following aspects by the Ethics Committee on Animal Use: 1) a proper rationale for the use of animals; 2) whether the species and number of animal will be appropriate for generating new data; 3 ) availability of proper facilities and equipment for handling animals ethically; 4) description of procedures to minimize animal discomfort and pain, such as the use of anesthetics and analgesics.

\section{Final remarks}

The use of animal models has largely contributed to a fuller understanding of the complex physiologic processes involved in the adaptation of the organism to physical exercise. It also shed light on the interactions between physical exercise and pathologies, and on the prevention and treatment of diseases.

The choice for animal models is warranted not only because very often the use of humans is too restricted or outright improper, but also because animals may offer a great contribution to assessing the role of the genetic profile in the response to exercise training. A new generation of exercise physiologists, pharmacologists and biochemists may, therefore, profit from the chance of studying the molecular mechanisms involved in a range of diseases and the role of genetics in human health and physical performance, thus consolidating a solid knowledge base in Exercise Sciences.

Physical Education in Brazil has reached a solid status, and professionals should embrace their key responsibility of producing and spreading knowledge, values and experiences, becoming thus agents of change in society. We should not be passive recipients of knowledge produced abroad, but innovative professionals informed by our own practices and studies in both humans and animals. In this sense, it is critical to disrupt any remaining prejudices to give basic research in Exercise Sciences the status it deserves. This is indeed an educational endeavor that should involve Physical Education professionals, undergraduate students from public and private universities and the population in general to reappraise the contributions of the area and to support research using animal models.

\section{References}

1. Harvey W. Exercitatio Anatomica de Motu Cordis et Sanguinis in Animalibus. Frankfurt; 1628. doi:10.1017/ CBO9781107415324.004.

2. Regnault H. Cours Élémentaire de Chimie. Paris; 1849.

3. Buskirk E. The emergence of exercise physiology in physical educantion. In: Brooks G, ed. Perspectives on the American Discipline of Physical Education. Champaign IL: Human Kinetics Publishers; 1981:55-74. 
4. Neiva CM, Guerino MR, Mello MAR de. Análise dos efeitos da desnutrição proteico-calórica sobre as respostas ao exercício agudo (single section): parâmetros metabólicos. Motriz. 1999;1(1):32-43.

5. Fletcher WM. Lactic acid in amphibian muscle. J Physiol. 1907;35(4):247-309.

6. Krogh A. The rate of diffusion of gases through animal tissues, with some remarks on the coefficient of invasion. J Physiol. 1919;52(6):391-408.

7. Krogh A. The number and distribution of capillaries in muscles with calculations of the oxygen pressure head necessary for supplying the tissue. J Physiol. 1919;52(6):409-415.

8. Hill A. Muscular Activity, Herter Lectures. Sixteenth. Baltimore: Williams \& Wilkins Company; 1926.

9. Benedict F. Vital Energetics: A Study in Comparative Basal Metabolism. Washington, DC: Carnegie Institution; 1938.

10. Krebs HA, Salvin E, Johnson WA. The formation of citric and alpha-ketoglutaric acids in the mammalian body. Biochem $\mathrm{J}$. 1938;32(1):113-117.

11. Kennedy EP, Lehninger AL. The products of oxidation of fatty acids by isolated rat liver mitochondria. J Biol Chem. 1950;185(1):275-285.

12. Ekblom B, Astrand PO, Saltin B, Stenberg J, Wallström B. Effect of training on circulatory response to exercise. J Appl Physiol. 1968;24(4):518-528.

13. Astrand PO, Ekblom B, Goldbarg AN. Effects of blocking the autonomic nervous system during exercise. Acta Physiol Scand. 1971;82(3):18A-19A. doi:10.1111/j.1748-1716.1971.tb05024.x.

14. Tipton CM. Training and bradycardia in rats. Am J Physiol. 1965;209(6):1089-1094.

15. Tipton CM. Animal models and their importance to human physiological responses in microgravity. Med Sci Sports Exerc. 1996;28(10 Suppl):S94-100.

16. Tipton CM, Sebastian LA. Dobutamine as a countermeasure for reduced exercise performance of rats exposed to simulated microgravity. J Appl Physiol. 1997;82(5):1607-1615.

17. Tipton CM. Determinants of VO2 max: insights gained from non-human species. Acta Physiol Scand Suppl. 1986;556:33-43.

18. Tipton CM. A perspective: animals, exercise research, and Medicine \&amp; Science in Sports \&amp; Exercise. Med Sci Sports Exerc. 2001;33(12):1981-1982.

19. Sherman WM, Plyley MJ, Sharp RL, Van Handel RM, McAllister WJ, Fink DL, et al. Costillet al. Muscle glycogen storage and its relationship with water. Int J Sports Med. 1982;3(1):22-24. doi:10.1055/s-2008-1026056.

20. Kuipers H, Costill DL, Porter DA, Fink WJ, Morse WM. Glucose feeding and exercise in trained rats: mechanisms for glycogen sparing. J Appl Physiol. 1986;61(3):859-863.

21. Kirwan JP, Costill DL, Flynn MG, Neufer PD, Fink WJ, Morse WM. Effects of increased training volume on the oxidative capacity, glycogen content and tension development of rat skeletal muscle. Int J Sports Med. 1990;11(6):479-483. doi:10.1055/s-2007-1024841.

22. Pattwell DM, Patwell DM, McArdle A, Morgan JE, Patridge TA, Jackson MJ. Release of reactive oxygen and nitrogen species from contracting skeletal muscle cells. Free
Radic Biol Med. 2004;37(7):1064-1072. doi:10.1016/j. freeradbiomed.2004.06.026.

23. McArdle A, Pattwell D, Vasilaki A, Griffiths RD, Jackson MJ. Contractile activity-induced oxidative stress: cellular origin and adaptive responses. Am J Physiol Cell Physiol. 2001;280(3):C621-7.

24. Evans DL, Rose RJ, Knight PK, Cluer D, Saltin B. Oxygen uptake in the racing camel at rest and during treadmill exercise. Acta Physiol Scand Suppl. 1994;617:40-48.

25. Knight PK, Rose RJ, Evans DL, Cluer D, Henckel P, Saltin B. Metabolic responses to maximal intensity exercise in the racing camel. Acta Physiol Scand Suppl. 1994;617:61-77.

26. Lindholm A, Saltin B. The physiological and biochemical response of standardbred horses to exercise of varying speed and duration. Acta Vet Scand. 1974;15(3):310-324.

27. Westerlind KC, Fluckey JD, Gordon SE, Kraemer WJ, Farrell PA, Turner RT. Effect of resistance exercise training on cortical and cancellous bone in mature male rats. J Appl Physiol. 1998;84(2):459-464.

28. Devor ST, Faulkner JA. Regeneration of new fibers in muscles of old rats reduces contraction-induced injury. J Appl Physiol. 1999;87(2):750-756.

29. Carlson BM, Faulkner JA. Muscle regeneration in young and old rats: effects of motor nerve transection with and without marcaine treatment. J Gerontol A Biol Sci Med Sci. 1998;53(1):B52-7.

30. Holloszy JO. Biochemical adaptations in muscle. Effects of exercise on mitochondrial oxygen uptake and respiratory enzyme activity in skeletal muscle. J Biol Chem. 1967;242(9):2278-2282.

31. Herzog W, Zatsiorsky V, Prilutsky BI, Leonard TR. Variations in force-time histories of cat gastrocnemius, soleus and plantaris muscles for consecutive walking steps. J Exp Biol. 1994;191:19-36.

32. Thorner W. New data on the physiology of training; clinical examination of heart and blood in endurance runs of growing dogs. Arbeitsphysiologie; Int Zeitschrift für Angew Physiol. 1949;14(2):116-136.

33. Mangili F, Cuttica F. Kinetics of cardiocirculatory adaptations during exercise in dogs. Boll della Soc Ital di Biol Sper. 1964;40(24):Suppl:2080-3.

34. Donald DE, Ferguson D. Response of heart rate, oxygen consumption, and arterial blood pressure to graded exercise in dogs. Proc Soc Exp Biol Med. 1966;121(2):626-630.

35. Vanhoutte P, Lacroix E, Leusen I. The cardiovascular adaptation of the dog to muscular exercise. Role of the arterial pressoreceptors. Arch Int Physiol Biochim. 1966;74(2):201-222.

36. Berkinelit MB, Kovalev SA, Smolianinov V V, Chaŭlakhian LM. Determination of basic electric characteristics of the myocardium of the ventricle in frogs. Biofizika. 1965;10(5):861-867.

37. Padykula HA, Gauthier GF. Cytochemical studies of adenosine triphosphatases in skeletal muscle fibers. J Cell Biol. 1963;18(1):87107. doi:10.1083/JCB.18.1.87.

38. Edelman JC, Edelman PM, Kniggee KM, Schwartz IL. Isolation of skeletal muscle nuclei. J Cell Biol. 1965;27(2):365-377.

39. Wierzuchowski M. Two paths of glucose utilization during heavy exercise in the dog. Am J Physiol. 1966;211(1):19-37. 
40. Hendricks HB, Aberle ED, Jones DJ, Martin TG. Muscle fiber type, rigor development and bone strength in dobule muscled cattle. J Anim Sci. 1973;37(6):1305-1311.

41. Kambadur R, Sharma M, Smith TP, Bass JJ. Mutations in myostatin (GDF8) in double-muscled Belgian Blue and Piedmontese cattle. Genome Res. 1997;7(9):910-916.

42. Carey RM, Wang ZQ, Siragy HM. Role of the angiotensin type 2 receptor in the regulation of blood pressure and renal function. Hypertens (Dallas, Tex 1979). 2000;35(1 Pt 2):155-163.

43. Visioli O, Rinetti M, Colombi L, Barbaresi F. Cardiac hypertrophy after muscular stress. Myocardial lipids modifications in rat. Mal Cardiovasc. 1965;6(4):531-535.

44. McMullen JR, Shioi T, Zhang L, et al. Phosphoinositide 3-kinase(p110alpha) plays a critical role for the induction of physiological, but not pathological, cardiac hypertrophy. Proc Natl Acad Sci U S A. 2003;100(21):12355-12360. doi:10.1073/ pnas. 1934654100.

45. ACSM. Acsm Honor / Citation Awards. www.acsm.org. Published 2016. Accessed September 16, 2016.

46. ISI. National Sciece Indicators, USA. Base Deluxe - SCI/2010 MEC CAPES Coleta. 2010.

47. Quinn R. Comparing rat's to human's age: How old is my rat in people years? Nutrition. 2005;21(6):775-777.

48. APS. Resource Book for the Design of Animal Exercise Protocols.; 2006.

49. McCarthy C. Bioethics of Laboratory Animal Research. 1st ed. Washington, DC: ILAR J.; 1999.

50. Perry P. The ethics of animal research: a UK perspective. ILAR J. 2007;48(1):42-46.
51. Russell W, Burch R. 1959. The Principles of Humane Experimental Technique. London: Methuen and Co. [Reissued: Universities Federation for Animal Welfare, Herts, UK]; 1992.

52. MCTI. Normativas Do CONCEA. 2nd ed. Brasília; 2015.

\section{Acknowledgments}

K.D.A.; B.R.; A.Z.; E.M.O.; F.S.E.; M.A.D.; P.C.B.; P.P.S.; S.L.A. received financial support from Fundação de Amparo à Pesquisa do Estado de São Paulo (FAPESP: 2014/23703-0, 2014/50673-4, 2013/14788-9, 2015/11223-6, 2015/04948-4, 2014/23229-6, 2012/20141-5, 2011/02126-6, 2011/14895-4), Fundação de Amparo à Pesquisa do Estado do Rio de Janeiro (FAPERJ: E26/110.166/2014), Conselho Nacional de Pesquisa e Desenvolvimento (CNPq: 405264/2015-1, 476515/2012-2, 441514/2014-6, 456051/2014-7, 457200/2014-6) and Coordenação de Aperfeiçoamento de Pessoal de Nível Superior (CAPES: 88881. 062178/2014-01). We thank Andre Rogow for his help in the search for past studies involving animal experimentation.

\section{Corresponding author}

Kátia De Angelis

Universidade Nove de Julho, São Paulo, SP, Brasil

Email: prof.kangelis@uni9.pro.br

Manuscripted received on September 19, 2016

Manuscripted accepted on November 18, 2016

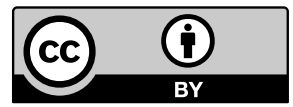

Motriz. The Journal of Physical Education. UNESP. Rio Claro, SP, Brazil - eISSN: 1980-6574 - under a license Creative Commons - Version 3.0 